Advances in Cement Research Volume 30 Issue 4

Processing and product characteristics of a blended cement grout incorporating polycarboxylate ether superplasticiser

Isaacs, Hayes, Rawlinson et al.
Advances in Cement Research, 2018, 30(4), 148-158 https://doi.org/10.1680/jadcr.17.00102 Paper 1700102 i

Qe

Institution of Civil Engineers

publishing

\title{
Processing and product characteristics of a blended cement grout incorporating polycarboxylate ether superplasticiser
}

Matthew Isaacs

University of Surrey, Guildford, UK

Martin Hayes

National Nuclear Laboratory, Warrington, UK

Steven Rawlinson

National Nuclear Laboratory, Warrington, UK

Michael Angus

National Nuclear Laboratory, Warrington, UK

Adam Qaisar

National Nuclear Laboratory, Warrington, UK

\section{Steven Christie}

Loughborough University, Loughborough, UK

Steven Edmondson

University of Manchester, Manchester, UK

David Read

University of Surrey, Guildford, UK; National Physical Laboratory,

Teddington, UK (corresponding author: d.read@surrey.ac.uk)

Superplasticisers improve the flow properties of cement and offer a number of operational advantages to producers of radioactive waste. Research is underway to clarify their mode of interaction using a bespoke, purified polycarboxylate ether (PCE) superplasticiser in controlled trials. A large-scale $\left(200 \mathrm{dm}^{3}\right)$ product was prepared with a mix of ground granulated blast-furnace slag and ordinary Portland cement (9:1 mix) and tested using methods established by the UK nuclear industry to assess grout performance. The product met the essential criteria for a radioactive waste encapsulation grout. Laboratory-scale studies utilising a ${ }^{14} \mathrm{C}$-labelled superplasticiser and its components were employed to better understand the mechanisms involved and to determine the location and distribution of the superplasticiser within cured cement monoliths. The results suggest that a PCE superplasticiser may enable the use of cement industry standard powders for encapsulation processes, allowing lower water content matrices and mitigating the risk of future powder supply issues.

\section{Introduction}

Solid intermediate level radioactive waste (ILW) has been generated for more than 60 years at nuclear-licensed sites throughout the UK. The wastes are currently located in vaults and silos on the various operational sites or are being processed directly as they arise for storage as encapsulated waste products. The plans for their safe packaging typically involve conditioning with cementitious grouts by either direct infill or by means of an in-drum mixing process. The aim is to produce a passively safe waste package in which the radioactive components are immobilised and can be stored above ground until a national geological disposal facility (GDF) becomes available. Concretes and grouts will also be used extensively in the construction and backfilling of a GDF.

Typical cementitious grout formulations for the encapsulation of ILW comprise blends of cement powders produced to a nuclear industry specification developed for Sellafield Limited (SL), consisting of ordinary Portland cement (CEM I) with either ground granulated blast-furnace slag (GGBS) or pulverised-fuel ash as the supplementary cementitious material. This specification differs from the equivalent British (BS EN 197-1:2011 (BSI, 2011)) and European standards in a number of respects, and is aimed at minimising variability in performance to meet the required processing and product quality criteria for waste packages. Grout powder formulations are developed to provide sufficient fluidity to ensure the waste is adequately infilled. However, the amount of water added to achieve sufficient fluidity is still in excess of that required for cement hydration and can result in the formation of residual bleed liquor from the cured product and an increase in the porosity and/or permeability of the waste form (Young et al., 2013). Although bleed water is typically allowed to evaporate, the excess pore water may promote reactive metal corrosion over prolonged time scales and hence reduce the long-term integrity of ILW products. A further consequence of the use of powders to a nuclear specification for ILW encapsulation is that it is becoming increasingly difficult to source a continuous and consistently performing supply - a situation exacerbated by the very low usage for encapsulation in comparison with annual powder production figures for the construction industry as a whole. In addition, the testing required to ensure appropriate quality assurance is both time consuming and costly.

As a result of these issues, several waste producers have considered incorporating organic superplasticisers into grout formulations. These are a specific class of cement additives known as high range water reducers and have been used routinely in the production of concretes for the civil construction industry over the past four decades (e.g. Baum and Ben-Bassat, 1999). They allow a reduction in the water to cement ratio while maintaining or imparting extreme fluidity to the mix and increasing the early strength of the concrete (Uchikawa et al., 1997). The incorporation of superplasticisers 
in cementitious waste forms would provide a major benefit to immobilisation plants since it would mask variability in performance from the wider-specification cement industry standard powders, thereby reducing the requirement for additional nuclear industry specified parameters, mitigating long-term powder supply risks and reducing the costs of powder production and quality assurance testing.

There are additional benefits to future waste immobilisation processes. These include

- enhanced fluidity of grout formulations, resulting in improved penetration of the waste and reducing waste form voidage

- reduction or elimination of bleed water

- reduced long-term metal corrosion rates, which may enhance package integrity owing to minimisation of water content in the grout formulation

- enhanced self-levelling capabilities, allowing the same grout formulation to be used for infilling and capping and thereby simplifying processing operations.

Despite these potential benefits, previous research has indicated that the solubility of certain radionuclides in a free aqueous solution can be increased by several orders of magnitude in the presence of superplasticisers, whereas the adsorption of metal cations may be inhibited (Greenfield et al., 1998; Young et al., 2013). Although superplasticisers do not appear to cause any significant difference in cement hydration products formed after $28 \mathrm{~d}$ (Lothenbach et al., 2007; Puertas et al., 2005), their use can affect the composition of pore waters, both enhancing the concentration of organic carbon as well as altering levels of cement-derived ions such as $\mathrm{Na}^{+}$or $\mathrm{SO}_{4}{ }^{2-}$ (Leemann et al., 2011; Wieland et al., 2014). Higher molecular weight organics present in polycarboxylate ether (PCE) superplasticisers show preferential uptake; thus, the organics remaining in solution are likely to be residual monomers and oligomers (Winnefeld et al., 2007). Finally, it should be noted that, due to variations in chain density, chain length and backbone length, each superplasticiser can have its own complexation behaviour and thus the results obtained from one superplasticiser may not be representative of others (Fantinel et al., 2004).

Current commercial proprietary products are primarily based on PCE graft copolymers comprising a polyacrylate backbone onto which polyethylene oxide (PEO) side chains are grafted. They are conceptually referred to as 'comb polymers', with the generic structure shown in Figure 1.

The structure of the PCE-PEO polymer is likely to change over time, to compensate for changes in cement properties. However, while minor changes in structure are considered less likely to affect the radionuclide complexing properties of the product, proprietary superplasticisers also typically contain a

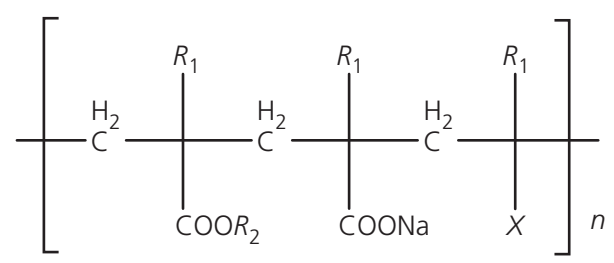

Figure 1. Generic polyacrylate copolymer

range of minor adjuncts to improve performance in the intended application. These include the following.

- Diethanol isopropanolamine (DEIPA) or other accelerators that overcome the retarding effect of the polycarboxylate component and boost early strength. DEIPA is known to enhance aluminate, GGBS and pulverised-fuel ash hydration.

- De-foamers to minimise entrained air. These are usually amine based although dibutyl phthalate and tributylphosphate find use in some applications.

- Hydroxycarboxylic acid such as sodium gluconate ( $2 \%)$, a known complexant, to prevent over-rapid adsorption of the PCE onto the aluminate phase.

- Biocides, which are added to prolong the shelf life of the superplasticiser.

The resulting proprietary formulations are thus complex and subject to frequent variation. As a small-scale user, the nuclear industry has no control over variables that may significantly affect the chemistry of the waste forms and the performance of a GDF. Consequently, an experimental programme was undertaken to synthesise a pure PCE superplasticiser, without the adjuncts outlined above, with the purpose of identifying individual complexants and mitigating radionuclide solubilisation (Isaacs et al., 2017). However, it is also necessary to assess if the synthesised PCE material generates the desired high fluidity enhancement properties at low water contents when incorporated into typical grouts used for ILW encapsulation. This paper details the results of a full-scale grout mixing trial incorporating the synthesised PCE into a blended GGBS/Portland cement mix to assess both initial processing characteristics and preliminary product evolution data.

\section{Experimental details}

A large-scale $\left(200 \mathrm{dm}^{3}\right)$ product was prepared, approximately half the scale of SL's current encapsulation plant products, using a Colcrete SD10 colloidal grout mixer with a cast-steel discar and a maximum batch capacity of $285 \mathrm{dm}^{3}$ with an associated single-paddle holding tank. The mix was conducted on a 9:1 weight/weight (w/w) GGBS:Portland cement (CEM I) mix, at a water/solids (w/s) ratio of 0.31 and a PCE loading of $0.5 \mathrm{vol} / \mathrm{w} \%$, based on the total weight of added powders. 
The GGBS was obtained from Hanson Cement's Scunthorpe works and complied with BS EN 15167-1:2006 (BSI, 2006) with a fineness of $517 \mathrm{~m}^{2} / \mathrm{kg}$ and specific gravity of $2 \cdot 91$. The cement component used was CEM I $42 \cdot 5 \mathrm{~N}$ with a fineness of $347 \mathrm{~m}^{2} / \mathrm{kg}$ and specific gravity of $3 \cdot 13$, obtained from Hanson Cement's Ribblesdale works, complying with both BS EN $197-$ 1:2011 (BSI, 2011) and the technical specification (Angus et al., 2011) for the supply of powders for the encapsulation of ILW at current SL encapsulation plants. The water used was Workington mains water and the PCE was a bespoke synthesised polymer (Isaacs et al., 2017). The detailed mix design used in the trial is shown in Table 1. The chemical and mineralogical composition of the CEM I and GGBS materials used, as determined by X-ray fluorescence and quantitative X-ray diffraction, is shown in Table 2.

\section{Preparation and characterisation of superplasticiser}

The synthesised PCE was prepared by means of free radical aqueous polymerisation (Figure 2) using sodium methacrylate $(16 \cdot 1 \mathrm{~g}, 0 \cdot 148 \mathrm{~mol})$, polyethylene glycol methyl ether methacrylate $(47.45 \mathrm{~g}, 0.0493 \mathrm{~mol})$ and methallyl sulfonate $(3.26 \mathrm{~g}$, $0.0197 \mathrm{~mol})$ in deionised water $\left(192 \mathrm{~cm}^{3}\right)$ with sodium persulfate $(2.5 \mathrm{~g}, 0.0105 \mathrm{~mol})$ as the initiator. The reaction was carried out at $80^{\circ} \mathrm{C}$ for $2 \mathrm{~h}$. All the chemicals were obtained from Sigma-Aldrich unless stated otherwise. The molar mass

Table 1. Large-scale grout mix design incorporating PCE superplasticiser

$\begin{array}{lc}\text { Material } & \text { Amount } \\ \text { GGBS } & 346.7 \mathrm{~kg} \\ \text { CEM I } & 38.5 \mathrm{~kg} \\ \text { Water } & 119.4 \mathrm{~kg} \\ \text { PCE } & 1.93 \mathrm{dm}^{3}\end{array}$

Table 2. Chemical analysis and physical properties of cement and slag used

\begin{tabular}{|c|c|c|}
\hline & CEM I & GGBS \\
\hline Silicon dioxide $\left(\mathrm{SiO}_{2}\right)$ : wt\% & $20 \cdot 3$ & $35 \cdot 4$ \\
\hline Calcium oxide $(\mathrm{CaO})$ : wt\% & $65 \cdot 1$ & $38 \cdot 4$ \\
\hline Aluminium oxide $\left(\mathrm{Al}_{2} \mathrm{O}_{3}\right)$ : wt\% & $5 \cdot 0$ & $11 \cdot 5$ \\
\hline Ferric oxide $\left(\mathrm{Fe}_{2} \mathrm{O}_{3}\right)$ : wt $\%$ & $2 \cdot 1$ & $0 \cdot 3$ \\
\hline Magnesium oxide (MgO): wt\% & $2 \cdot 3$ & 9 \\
\hline Sulfur trioxide $\left(\mathrm{SO}_{3}\right): \mathrm{wt} \%$ & $3 \cdot 1$ & 0.03 \\
\hline Potassium oxide $\left(\mathrm{K}_{2} \mathrm{O}\right)$ : wt\% & 0.6 & 0.6 \\
\hline Sodium oxide $\left(\mathrm{Na}_{2} \mathrm{O}\right)$ : wt\% & 0.4 & 0.4 \\
\hline Manganese oxide (MnO): wt\% & $N D^{a}$ & 0.5 \\
\hline Chlorides: wt\% & 0.04 & 0.02 \\
\hline Loss on ignition: wt\% & $1 \cdot 1$ & 0.8 \\
\hline Moisture content: wt\% & ND & 0.02 \\
\hline Specific gravity & $3 \cdot 13$ & $2 \cdot 91$ \\
\hline Fineness: $\mathrm{m}^{2} / \mathrm{kg}$ & 347 & 517 \\
\hline $\mathrm{C}_{3} \mathrm{~S}: \mathrm{wt} \%$ & $58 \cdot 2$ & ND \\
\hline $\mathrm{C}_{2} \mathrm{~S}: \mathrm{wt} \%$ & $18 \cdot 1$ & ND \\
\hline $\mathrm{C}_{3} \mathrm{~A}: \mathrm{wt} \%$ & $8 \cdot 8$ & ND \\
\hline
\end{tabular}

${ }^{\mathrm{a}}$ Not determined and polydispersivity of the PCE was determined using gel permeation chromatography (eluent $0 \cdot 1 \mathrm{M}$ sodium phosphate and azide buffer). The polydispersivity index (PDI) was calculated by dividing the weight average molecular weight $\left(M_{\mathrm{w}}\right)$ by the number average molecular weight $\left(M_{\mathrm{n}}\right)$. The PCE was determined to have an $M_{\mathrm{n}}$ of $9316 \mathrm{Da}$, an $M_{\mathrm{w}}$ of 20850 and a PDI of 2.24. ${ }^{1} \mathrm{HNMR}$ (Bruker 400) spectra were obtained on the PCE for further characterisation: $\delta \mathrm{H}\left(400 \mathrm{MHz}, \mathrm{D}_{2} \mathrm{O}\right) 0 \cdot 5-1 \cdot 3$ $\left(\mathrm{m}, \mathrm{CH}_{3}\right) 1 \cdot 5-2 \cdot 0\left(\mathrm{~m}, \mathrm{CH}_{2}\right) 3.55\left(\mathrm{~s}, \mathrm{O}-\mathrm{CH}_{2}\right) 4.03\left(\mathrm{~s}, \mathrm{CH}_{2}-\mathrm{SO}_{3}\right)$.

\section{Mix and sample preparation}

The mix was conducted by adding the required quantity of PCE to water in the mixer, pre-chilled to below $8^{\circ} \mathrm{C}$ prior to powder addition. The chilling of water is consistent with current SL encapsulation plant processes to control the reaction rate and ensure that maximum waste package temperatures remain within acceptable limits $\left(<100^{\circ} \mathrm{C}\right)$. The powders were then added from a single hopper over an approximate 8 min period with the CEM I component added first. They were mixed at a fixed shaft rotation speed of $2000 \mathrm{rpm}$ for a further $3 \mathrm{~min}$ until mixing of the powders was complete, termed $t=0$. The grout mix was then transferred to a lowshear holding tank and mixed for a further $150 \mathrm{~min}$, termed $t=150 \mathrm{~min}$, at $30 \mathrm{rpm}$.

The grout prepared by the method described above was subjected to a number of small-scale nuclear industry standard test protocols to ensure it met a set of key criteria for current encapsulation processes, including grout fluidity, bleed and setting time.

Small batches of cement with the same mix ratios were also prepared at a $5 \mathrm{~kg}$ scale in the laboratory to provide a comparison with the large-scale product. The powder ingredients were weighed and mixed for $1 \mathrm{~h}$ using a Pascal Lab powder mixer. The PCE mix and mains water at room temperature were weighed and added to a stainless steel mixing bowl positioned on a Kenwood KMX54 food mixer. The solution was stirred and the pre-weighed powder added at a constant rate over a $5 \mathrm{~min}$ period. The paste was allowed to mix for a further 5 min before use in fluidity tests or poured into moulds.

\section{Fluidity}

As grouts are required to fully penetrate the waste in order to minimise voidage (Angus et al., 2011), fluidity is a key criterion. Fluidity was measured by the Colcrete Flow Channel ('Colflow') technique, a proprietary fluidity test developed by Colcrete Ltd and based on the method defined in BS EN 13395-2:2002 (BSI, 2002). In this test, a standard volume of grout $\left(1 \cdot 14 \mathrm{dm}^{3}\right)$ is allowed to fall from a cone (tundish) into a horizontal channel under gravity and the subsequent flow distance is measured. The flow must be maintained for a set period after mixing (150 min), which is the longest period for which the SL encapsulation plants may hold a batch prior to use. 

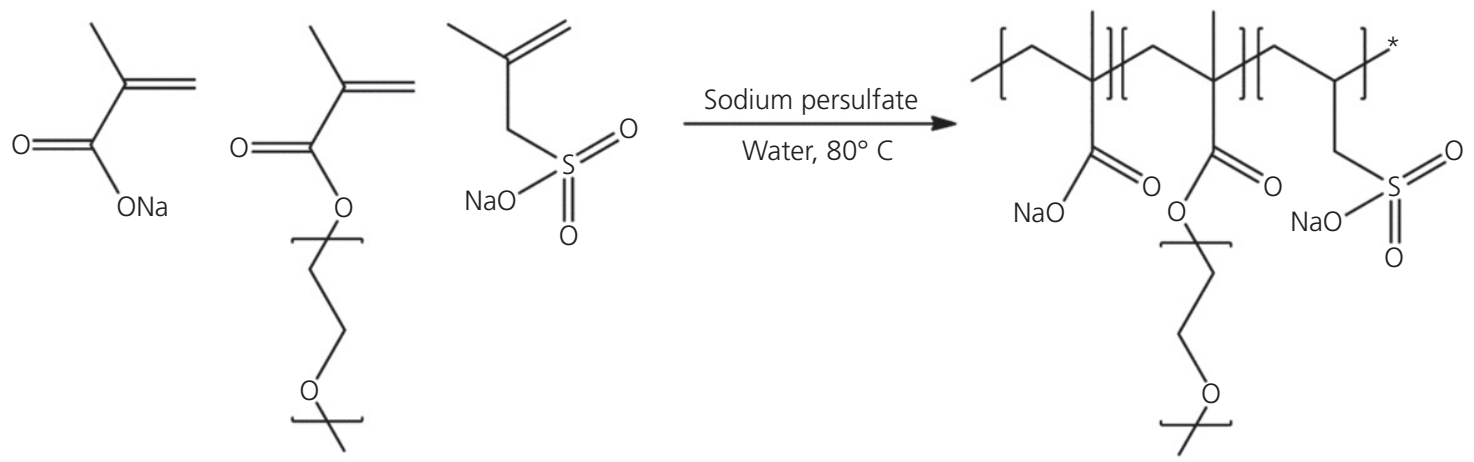

Figure 2. Synthesis scheme for the bespoke polycarboxylate superplasticiser

\section{Bleed}

Surface bleed is an important parameter since any residual liquor remaining after cement set may require treatment as an active liquor stream. It is thus desirable that cement products set with zero bleed after $24 \mathrm{~h}$ curing. Bleed was measured for mix times of $t=0$ and $t=150 \mathrm{~min}$ by placing $100 \mathrm{~cm}^{3}$ of grout in a measuring cylinder, sealing with a rubber tube and recording the amount of visible water above the grout as $\mathrm{vol} / \mathrm{vol} \%$ of the original grout volume after curing for $24 \mathrm{~h}$ at $20 \pm 1^{\circ} \mathrm{C}$ with $>90 \%$ relative humidity $(\mathrm{RH})$.

\section{Set time}

The setting time of grout samples is important in order to achieve satisfactory throughput while ensuring that subsequent process operations will not damage the grouted product. The set time of grout samples mixed for $t=0$ and $t=150 \mathrm{~min}$ was determined by a manual Vicat apparatus based on the method described in BS EN 196-3:2005+A1:2008 (BSI, 2008). After mixing for the required period, grout samples were placed in a plastic Securitainer ( $49 \mathrm{~mm}$ diameter $\times 75 \mathrm{~mm}$ height) to a depth of $40 \mathrm{~mm}$. The container was lidded and the sample cured at $20 \pm 1{ }^{\circ} \mathrm{C}$ and $>90 \% \mathrm{RH}$ with periodic testing to determine both initial and final set by measuring the resistance to penetration of special needles into the cement paste.

\section{Viscosity}

In order to gain a further measure of rheological properties, the viscosity of samples mixed for $t=0$ and $t=150 \mathrm{~min}$ was measured at a shear rate of $106 \mathrm{~s}^{-1}$, on a descending ramp from $262 \mathrm{~s}^{-1}$, following a $2 \mathrm{~min}$ pre-shear at $262 \mathrm{~s}^{-1}$, using a Mettler RM265 rheometer fitted with an MSR-2 paddle. This is a test protocol developed by the nuclear industry to provide an indication of the feasibility of in-drum mixing of sludge or slurry wastes with cement powders to produce satisfactory products.

\section{Heat of hydration}

The heat of hydration from the cement curing reaction was determined on grout samples mixed for $t=0$ and $t=150 \mathrm{~min}$ by means of isothermal conduction calorimetry at $35^{\circ} \mathrm{C}$ using a
TAMair calorimeter supplied by Thermometric AB, Sweden. A $3.03 \mathrm{~g}$ sample was placed in the calorimeter after mixing and analysis was conducted against a sand reference sample of the same mass over $45 \mathrm{~h}$. The results were compared to a control mix of 9:1 w/w GGBS:Portland cement (CEM I), at a w/s ratio of 0.31 without incorporation of PCE, utilising the powders described in Table 2. The control mix was conducted at small scale using a low-shear planetary Hobart mixer. Powders were added to the water (chilled to $7^{\circ} \mathrm{C}$ ) over a $5 \mathrm{~min}$ period, followed by a further $15 \mathrm{~min}$ of mixing, prior to placing the sample $(3 \mathrm{~g})$ in the TAMair isothermal calorimeter at $35^{\circ} \mathrm{C}$. Sand $(3.29 \mathrm{~g})$ was again used as the reference material. A temperature of $35^{\circ} \mathrm{C}$ was selected as this is a typical higher processing temperature in waste encapsulation plants. The control mix was conducted at small scale and at $t=0$ as the mix was too thick at the low w/s ratio studied without superplasticiser to mix successfully in the large-scale SD10 mixer.

Set samples of grout after mixing for $t=150 \mathrm{~min}$ were also subjected to a number of product quality tests to assess the processing characteristics of the superplasticised grout. These are standard tests undertaken within the nuclear industry, designed to assess how the properties of grout samples evolve over time and hence build confidence that satisfactory products can be obtained over prolonged storage periods.

\section{Strength}

The compressive strength of the PCE-incorporated grout mix was measured in duplicate on $100 \mathrm{~mm}$ cubes using an ELE International ADR Auto 2000/250 kN range compressive strength machine in accordance with BS EN 12390-3:2009 (BSI, 2009). The cubes were cured at $20 \pm 1^{\circ} \mathrm{C}$ and $>90 \% \mathrm{RH}$ over a $90 \mathrm{~d}$ period, with testing conducted at 7, 28 and $90 \mathrm{~d}$.

\section{Ultrasonic pulse velocity (UPV)}

An indirect measurement of strength development in the PCEincorporated grout mix was conducted in duplicate by way of an UPV test on $100 \mathrm{~mm}$ cubes cured at $20 \pm 1^{\circ} \mathrm{C}$ and $>90 \%$ RH over a $90 \mathrm{~d}$ period. Testing was conducted at 7, 14, 28, 56, 70 and $90 \mathrm{~d}$. 


\section{Dimensional stability}

The dimensional stability of set grout samples was tested at defined curing periods in quadruplicate on $25 \mathrm{~mm} \times 25 \mathrm{~mm}$ $\times 285 \mathrm{~mm}$ prisms cured at $20 \pm 1{ }^{\circ} \mathrm{C}$ and $>90 \% \mathrm{RH}$ in accordance with ASTM C 490 (ASTM, 2014) using a Heidenhain test frame and invar reference bar to monitor how the dimensions of the test samples change as hydration proceeds in comparison with a calibrated rod of known length. The prisms were wrapped in polythene with ends covered on de-moulding such that just the end studs were exposed in order to prevent the samples drying out over the curing period.

\section{Grout exotherm}

A $200 \mathrm{dm}^{3}$ product was prepared by pumping the grout after mixing for $t=150 \mathrm{~min}$ into a square-based mild steel mould of nominal volume $540 \mathrm{dm}^{3}$ in order to assess the exotherm at large-scale generated during the grout curing reaction. The grout was pumped at a rate of $40 \mathrm{dm}^{3} / \mathrm{min}$ from the SD10 mixer into the mould and the exotherm at the centre of the uncovered product was measured at an uncontrolled ambient temperature between $19 \cdot 5^{\circ} \mathrm{C}$ and $22 \cdot 9^{\circ} \mathrm{C}$. The exotherm was measured using a K-type thermocouple connected to a Yokogawa data logging system.

\section{X-ray microtomography of $200 \mathrm{dm}^{3}$ product}

The $200 \mathrm{dm}^{3}$ product was sectioned vertically using a diamond wire saw after $480 \mathrm{~d}$ hydration. Cores ( $25 \mathrm{~mm}$ diameter) were taken from cut faces at three depths (centre of core $60 \mathrm{~mm}$ from top, $40 \mathrm{~mm}$ from bottom and approximately central). The samples were crushed to provide suitably sized fragments for tomography to give optimum resolution given the constraints of the system's geometric magnification. The samples were scanned using a Bruker Skyscan 1172 system at $100 \mathrm{kV}$, $10 \mathrm{~W}, 0.2^{\circ}$ rotation step size, a $0.5 \mathrm{~mm}$ aluminium filter in place and at a pixel resolution of $0.75 \mu \mathrm{m}$.

\section{Distribution of superplasticiser within cured matrix}

Additional experiments were undertaken to assess the distribution of superplasticiser within the cement and the composition of expressed pore water. The former was assessed by ${ }^{14} \mathrm{C}$ labelling of the PCE using a spike of ${ }^{14} \mathrm{C}$-labelled methyl methacrylate, obtained from American Radiolabelled Chemicals Inc., in a scaled down synthesis of the method described above. $10 \mathrm{kBq}$ of this labelled material was used in a hand-mixed grout with the same mix ratios. The bleed was collected after $24 \mathrm{~h}$ and the activity measured. The blocks were sawn axially and autoradiographic images obtained, showing the PCE distribution in the cement sample.

\section{Pore expression}

The small-scale mix as detailed above produced cylindrical samples of GGBS grouts with dimensions of approximately $49 \mathrm{~mm}$ diameter and $75 \mathrm{~mm}$ length. Duplicate samples with superplasticiser dosed at $0 \cdot 5 \%$ and $1 \%$ by weight of cement (bwoc), plus corresponding blanks, were prepared. The samples were allowed to cure for $28 \mathrm{~d}$ under nitrogen. Each specimen was placed on the base of a press and the pressure increased gradually through the piston to $4000 \mathrm{psi}$ $(27 \mathrm{MPa})$. As the pressure increased, water was expressed from the samples and flowed through a hypodermic needle and a tube into a collection vessel. This system ensured that the sample was not exposed to air, avoiding carbonation (Clacher et al., 2013). The pore waters collected were analysed for the presence of organics by total organic carbon (TOC) analysis on a Sievers Innovox online analyser and their $\mathrm{pH}$ was measured.

\section{Results and discussion}

\section{Processing characteristics}

The processing characteristics of the grout mix incorporating PCE are shown in Table 3. The results for a 9:1 w/w GGBS/CEM I grout, w/s ratio of $0 \cdot 37$, incorporating SL specification powders of GGBS (fineness $410 \mathrm{~m}^{2} / \mathrm{kg}$ ) and CEM I (fineness of $328 \mathrm{~m}^{2} / \mathrm{kg}$ ) are shown for comparison. This latter mix was undertaken at $3 \mathrm{dm}^{3}$ scale using a standard mixing regime developed for testing powders for SL encapsulation plants and, although only small-scale, was developed to closely match the performance of large-scale mixing processes used in the current SL plants. The test involved adding powders to the mix water in a low-shear planetary Hobart mixer over a 5 min period while mixing, followed by a further $5 \mathrm{~min}$ of low-shear mixing. This was immediately followed by $10 \mathrm{~min}$ of highshear mixing, at which point $(t=0)$ mixing was complete. Low-shear mixing was then continued for a further $150 \mathrm{~min}$ hold-up ( $t=150 \mathrm{~min}$ ). The GGBS and CEM I powders for the

Table 3. Processing characteristics of superplasticised PCE grout and non-superplasticised SL specification grout

\begin{tabular}{|c|c|c|c|c|c|c|c|c|c|c|c|c|}
\hline \multirow[b]{2}{*}{ Mix formulation } & \multicolumn{2}{|c|}{ Fluidity: mm } & \multicolumn{2}{|c|}{$\begin{array}{c}\text { Grout } \\
\text { temperature: }{ }^{\circ} \mathrm{C}\end{array}$} & \multicolumn{2}{|c|}{ Bleed: \% } & \multicolumn{2}{|c|}{$\begin{array}{l}\text { Viscosity at } \\
106 s^{-1}: \text { Pa.s }\end{array}$} & \multicolumn{2}{|c|}{$\begin{array}{l}\text { Setting time, } \\
0 \text { min: } h\end{array}$} & \multicolumn{2}{|c|}{$\begin{array}{l}\text { Setting time, } \\
150 \text { min: } h\end{array}$} \\
\hline & $0 \mathrm{~min}$ & $150 \mathrm{~min}$ & $0 \mathrm{~min}$ & $150 \mathrm{~min}$ & $0 \mathrm{~min}$ & $150 \mathrm{~min}$ & $0 \mathrm{~min}$ & $150 \mathrm{~min}$ & Initial & Final & Initial & Final \\
\hline $\begin{array}{l}\text { 9:1 GGBS/CEM I, } 0.5 \mathrm{vol} / \mathrm{w} \\
\% \text { PCE, w/s }=0.31\end{array}$ & $>1360$ & $>1360$ & 21 & 26 & 2 & 0 & 0.08 & 0.08 & $>4$ & $>24$ & $>4$ & $<24$ \\
\hline $\begin{array}{l}9: 1 \text { GGBS/CEM I, } \\
w / s=0.37\end{array}$ & 650 & 600 & 21 & 19 & 0 & $<1$ & $0 \cdot 39$ & 0.42 & $N^{a}$ & ND & $>4$ & $<19$ \\
\hline
\end{tabular}

${ }^{\mathrm{a}}$ Not determined 
Advances in Cement Research

Volume 30 Issue 4
Processing and product characteristics

of a blended cement grout incorporating

polycarboxylate ether superplasticiser

Isaacs, Hayes, Rawlinson et al.
SL specification grout were obtained from Hanson Cement's Scunthorpe and Ribblesdale works, respectively.

The results in Table 3 indicate that the mix containing the PCE had a very high fluidity, in excess of the length of the Colcrete flow channel over the full period of hold-up mixing. This is despite the use of BS EN standard GGBS powder that was significantly finer than the current SL specification powder, and at a low w/s ratio of $0 \cdot 31$. Therefore, the mix significantly exceeded the current SL specification for satisfactory waste infill for current encapsulation grouts of a minimum $200 \mathrm{~mm}$ flow at $t=150 \mathrm{~min}$ (albeit with vibration applied to improve infill performance), and had a far higher fluidity than a standard SL specification grout of the same powder blend ratio, despite a $16 \%$ reduction in water content, over the full $2.5 \mathrm{~h}$ hold-up period. Consistent with the high fluidities obtained, the mix also retained a very low viscosity over the full period of hold-up mixing and, again, significantly lower than that obtained for the SL specification grout. No viscosity range is specified for SL grouts, since the fluidity requirement is based on the Colflow test. Nevertheless, it is worth noting that in-drum mixers of the type used at SL are capable of producing successful products at viscosities in excess of 7 Pa.s at $106 \mathrm{~s}^{-1}$. Therefore, the viscosities reported here are extremely low and may allow satisfactory infilling of products without mechanical vibration, thereby simplifying plant processes significantly.

As described previously, retained bleed liquor on set products is also an important parameter for plant processing. The results indicate that, while samples after hold-up in the mixer for $t=150 \mathrm{~min}$ had zero bleed and also met the current SL initial set criteria of $>4 \mathrm{~h}$ (enabling products to be moved without damage) and final set criteria of less than $24 \mathrm{~h}$, the product after initial mixing $(t=0)$ had approximately $2 \mathrm{vol} \%$ surface bleed after $24 \mathrm{~h}$ curing. The specification of bleed levels for powders in current encapsulation plants is based only on samples mixed for $t=150 \mathrm{~min}$ and therefore this does not, in itself, indicate an unacceptable product. However, the formation of this bleed liquor did result in the product failing the final SL set criterion at $24 \mathrm{~h}$ due to the production of a soft surface layer. It would be anticipated that this bleed level would be reduced on full-scale products $\left(500 \mathrm{dm}^{3}\right.$ in current SL plants and potentially up to $3000 \mathrm{dm}^{3}$ in future plants) due to the higher grout exotherms anticipated and hence this level of bleed on small-scale products is deemed acceptable. Furthermore, $0.5 \mathrm{vol} / \mathrm{w} \%$ PCE is at the upper limit of the range likely to be added. The results also indicated that preferential particle segregation was occurring on samples produced from short-term mixing. This will warrant further investigation in developing grout formulation envelopes for plant processes.

\section{Heat of hydration}

The development of heat flow and cumulative heat output at $35^{\circ} \mathrm{C}$ are shown in Figure 3. The data shown were normalised to the mass of total powders in the mix, due to the hydration of the superplasticised grout after mixing for $t=0$ and $t=150 \mathrm{~min}$, in comparison with the control mix without PCE. The time to reach the peak rate of heat output and the cumulative heat output after $24 \mathrm{~h}$ hydration at $35^{\circ} \mathrm{C}$ for each mix is shown in Table 4.

The mixes all showed a similar development of heat flow, with an initial sharp peak in heat output after the induction period followed by a broader lower secondary peak. The results indicate that the hydration reaction mechanisms were largely unaffected by the presence of PCE. The nature of the calorimetry methodology, in which samples were externally mixed prior to placement in the equipment, can also result in the loss of data associated with initial exothermic wetting and the induction period. Hence, the induction period was only partially observed in the PCE-incorporated mix at $t=150 \mathrm{~min}$ (not unexpected due to the residence time in the SD10 mixer holdup tank) and the control mix without PCE, but was clearly observed in the PCE-incorporated mix obtained at $t=0$ after only $3 \mathrm{~min}$ residence time in the mixer. The grouts all showed similar heat flow maxima of between $1.6 \mathrm{~mW} / \mathrm{g}$ and $1.73 \mathrm{~mW} / \mathrm{g}$, although the time to reach the maxima was

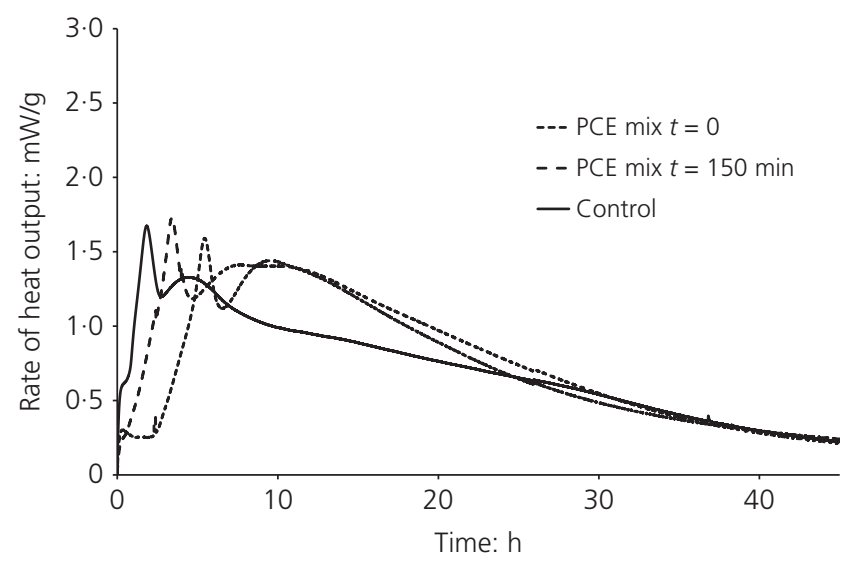

Figure 3. Rate of heat output for superplasticised 9:1 GGBS: CEM I, $0.31 \mathrm{w} / \mathrm{s}$ grout at $35^{\circ} \mathrm{C}$ mixed for $t=0$ and $t=150 \mathrm{~min}$ and control 9:1 GGBS:CEM I, $0.31 \mathrm{w} / \mathrm{s}$ grout at $t=0$

Table 4. Peak and cumulative heat output for superplasticised PCE and non-superplasticised (control) 9:1 GGBS/CEM I grouts at $\mathrm{w} / \mathrm{s}$ ratio of 0.31 at $35^{\circ} \mathrm{C}$

\begin{tabular}{|lccc|} 
Mix & $\begin{array}{c}\text { Peak rate } \\
\text { of heat output: } \\
\text { fW/g total } \\
\text { formulation }\end{array}$ & $\begin{array}{c}\text { Time to } \\
\text { peak } \\
\text { rate: } \mathbf{h}\end{array}$ & $\begin{array}{c}\text { Cumulative heat } \\
\text { output at } \mathbf{2 4} \mathbf{~ h :} \\
\mathbf{k J} / \mathbf{k g} \text { total } \\
\text { powders }\end{array}$ \\
\hline Control & 1.67 & 1.8 & 84 \\
PCE mix $t=0$ & 1.59 & 5.4 & 87 \\
PCE mix & 1.73 & 3.4 & 98 \\
$t=150$ min & & & \\
\hline
\end{tabular}


Advances in Cement Research

Volume 30 Issue 4
Processing and product characteristics

of a blended cement grout incorporating

polycarboxylate ether superplasticiser

Isaacs, Hayes, Rawlinson et al. delayed in mixes containing PCE. The latter is consistent with retardation of the initial hydration reaction, as is typical in cements amended with PCE (Hanehara and Yamada, 1999) and with the very high fluidities observed in the Colflow test. The initial peak is possibly attributable to early aluminate reactions and the depletion of calcium sulfate phases to form ettringite or AFm (aluminium iron monosulfate phase) (Hesse et al., 2011) in these low cement ratio formulations, with the secondary peak corresponding to the reaction of the alite $\left(\mathrm{C}_{3} \mathrm{~S}\right)$ phase in the cement to form the main products of hydration, C-S-H and $\mathrm{CH}\left(\mathrm{C}=\mathrm{CaO}, \mathrm{S}=\mathrm{SiO}_{2}, \mathrm{H}=\mathrm{H}_{2} \mathrm{O}\right)$ (Jansen et al., 2012). Microstructural evidence would be needed to support this hypothesis. The broad nature of the secondary peak may also include a contribution from initial GGBS hydration, given the fineness of the powder used.

The cumulative heat evolved after $24 \mathrm{~h}$ shown in Table 4 is currently limited by the specification for cement powders for ILW encapsulation plant processes to $<180 \mathrm{~kJ} / \mathrm{kg}$ in order to ensure that the hydrates within a cemented waste product matrix remain stable and that the product is not subject to internal pressurisation due to steam generation. Therefore, despite the use of high specific surface area GGBS powder in these grouts and the low w/s ratio, it can be observed that the cumulative heat was significantly below this level in all cases, with very little difference in the heat profile (and hence degree of hydration) between the PCE $t=0$ and control mixes after the initial retardation in the former mix. The PCE grout mix sample after $t=150 \mathrm{~min}$ had a higher cumulative heat output than either of the other samples from approximately $12 \mathrm{~h}$ of hydration, indicating a greater degree of hydration and possibly attributable to the increased surface area available for hydration effected by the longer mixing time. The cumulative heat outputs after $24 \mathrm{~h}$ are also of similar order to standard SL specification grouts at the high end of the cement blend ratio in typical encapsulation plant processes (3:1 GGBS/CEM I w/w ratio) and a standard w/s ratio of $0 \cdot 35$, which showed a heat output of $98 \mathrm{~kJ} / \mathrm{kg}$ after $24 \mathrm{~h}$ (Cann et al., 2015). This is perhaps not unexpected due to the higher GGBS/CEM I ratio in the cements tested in the present study being off-set by a lower w/s ratio, but does indicate that the systems studied were significantly below current SL specification limits for heat evolution.

\section{Product evolution studies}

The production of high strength is not a necessary prerequisite for grouted ILW products, with adequate guideline waste form strengths of $4 \mathrm{MPa}$ at $7 \mathrm{~d}$ and $7 \mathrm{MPa}$ after $90 \mathrm{~d}$ curing for cemented waste forms being previously assumed (Nirex, 2005). However, a typical strength gain pattern with curing time is sought as this gives an indication that the hydration process is proceeding in the anticipated manner without deleterious reactions occurring between the waste and matrix.

The compressive strengths of duplicate $100 \mathrm{~mm}$ cubes over a full $90 \mathrm{~d}$ curing period were characterised by a high degree of consistency. Average values are shown in Table 5, with product strength increasing over the $90 \mathrm{~d}$ testing period from $35.5 \mathrm{MPa}$ at $7 \mathrm{~d}$ to $71.8 \mathrm{MPa}$ after $90 \mathrm{~d}$ curing. This is a standard pattern of behaviour as the strength of a cementitious product is directly related to the microstructure of the hardened cement paste (Puertas et al., 2005). The cement and supplementary cementitious material (GGBS) hydrate to form products that fill pore spaces, with a resulting densification of the microstructure and increasing strength of the matrix., As shown in Table 5, the strengths obtained for the PCE-incorporated grout mix were higher at all test ages than those of the typical encapsulation grout produced with SL specification powders with a higher cement content (3:1 GGBS/CEM I w/w powder ratio and w/s ratio of $0 \cdot 35$ ), albeit mixed using the small-scale mix procedure and coarser powders. This shows the importance of the w/s ratio on the strength of a cement matrix at a given age.

In addition to direct measurement of the compressive strength of the grout matrix, an indirect non-destructive method of assessing strength development can be obtained by measuring the time taken for an ultrasonic pulse to pass through test specimens. As strength develops within the matrix, the time taken for an ultrasonic pulse to pass through the specimen decreases. Average UPV values for the test specimens are shown Table 6 along with results of the standard SL specification grout (3:1 GGBS/CEM I, w/s ratio of 0.35).

The UPV results for the PCE-incorporated grout show the anticipated increase with time commensurate with the increase in strength observed for this grout mix and the densification of the matrix with increased curing time. The results are also comparable to those of the SL specification grout at each time

Table 5. Compressive strength of superplasticised PCE grout and non-superplasticised SL specification grout

\begin{tabular}{llcc|} 
& \multicolumn{3}{c}{ Compressive strength: $\mathbf{M P a}$} \\
\cline { 2 - 4 } Mix formulation & $7 \mathrm{~d}$ & $28 \mathrm{~d}$ & $90 \mathrm{~d}$ \\
\hline $\begin{array}{c}\text { 9:1 GGBS/CEM I, 0.5 vol/w\% } \\
\text { PCE, w/s = 0.31 }\end{array}$ & 35.5 & 56.7 & 71.8 \\
3:1 GGBS/CEM I, w/s=0.35 & 21.6 & 47.0 & 64.7 \\
\hline
\end{tabular}

Table 6. UPV data for superplasticised PCE grout and non-superplasticised SL specification grout

\begin{tabular}{lccccccc} 
& \multicolumn{7}{c}{ UPV: $\mathbf{k m} / \mathbf{s}$} \\
\cline { 2 - 7 } Mix formulation & $7 \mathrm{~d}$ & $14 \mathrm{~d}$ & $28 \mathrm{~d}$ & $56 \mathrm{~d}$ & $70 \mathrm{~d}$ & $90 \mathrm{~d}$ \\
\hline $\begin{array}{c}\text { 9:1 GGBS/CEM I, } \\
0.5 \mathrm{vol} / \mathrm{W} \% \mathrm{PCE},\end{array}$ & 2.98 & 3.14 & 3.29 & 3.34 & 3.38 & 3.43 \\
$\begin{array}{l}\text { 0.31 W/s } \\
\text { 3:1 GGBS/CEM I, } \\
0.35 \mathrm{w} / \mathrm{s}\end{array}$ & 2.9 & $\mathrm{ND}^{\mathrm{a}}$ & 3.2 & 3.4 & 3.5 & 3.6 \\
\hline
\end{tabular}

${ }^{a}$ Not determined 
Advances in Cement Research

Volume 30 Issue 4
Processing and product characteristics of a blended cement grout incorporating polycarboxylate ether superplasticiser

Isaacs, Hayes, Rawlinson et al. interval, although marginally lower at later ages in contrast to the higher strengths observed in the compressive strength tests. The results therefore indicate that the development of cement microstructure in the PCE-incorporated grout matrix was consistent with that obtained for typical ILW encapsulation grouts.

An important criterion for grouted ILW products is their longterm physical stability in order to ensure that excessive cracking is minimised, radionuclide immobilisation is not compromised and hence to ensure that essentially monolithic products are produced over prolonged periods of storage. Dimensional stability is typically determined by measuring the change in length per unit length of prisms with curing time, with results expressed in microstrain $\left(10^{-4_{0}} \%\right.$ of movement). The accepted criterion for the dimensional stability of conventional Portland cement based matrices for ILW products lies between +1000 microstrain expansion $(+0 \cdot 1 \%)$ and -3000 microstrain contraction $(-0 \cdot 3 \%)$. In addition, cement systems are typically only viewed as acceptable as an encapsulation matrix once dimensional changes have stabilised. Figure 4 shows the average change in dimensions from four prisms over a $220 \mathrm{~d}$ curing period. The results indicate that the samples, despite being wrapped, initially underwent shrinkage to approximately -1200 microstrain $(-0 \cdot 12 \%)$. This is typically attributed to minor degrees of drying shrinkage resulting from water loss, which is difficult to avoid. Despite this, no visible cracking was observed either at the small or large scale. The samples subsequently stabilised after $125 \mathrm{~d}$ of curing. The PCE-incorporated grout mix thus shows dimensional changes well within currently accepted criteria for cement based ILW encapsulants.

\section{Large-scale grout exotherm and product assessment}

Figure 5 shows the measured peak centre line exotherm for the $200 \mathrm{dm}^{3}$ PCE-incorporated grout product at an ambient temperature cure $\left(19 \cdot 5-22 \cdot 9^{\circ} \mathrm{C}\right)$. The results indicate that, despite the use of higher specific surface area GGBS powders and a low w/s ratio, the maximum temperature reached was $55^{\circ} \mathrm{C}$ after $21 \mathrm{~h}$ curing. This is well below the currently accepted

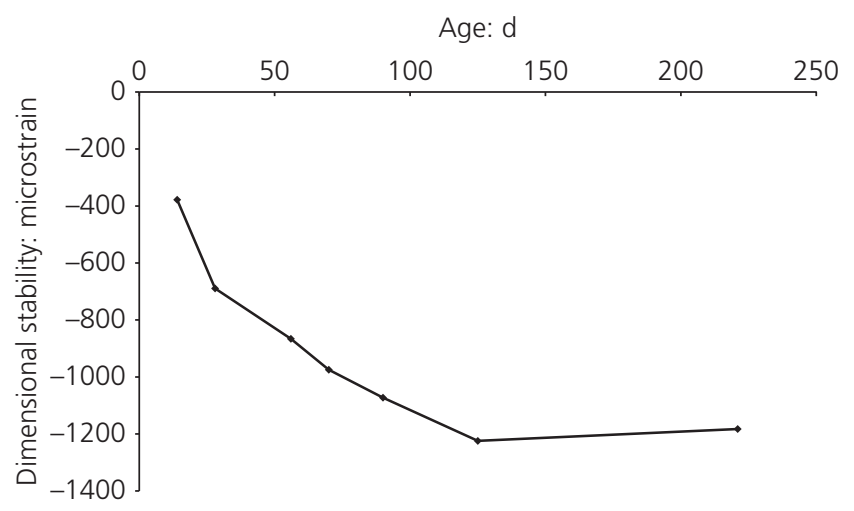

Figure 4. Average dimensional stability of prisms cast from PCE superplasticised grout

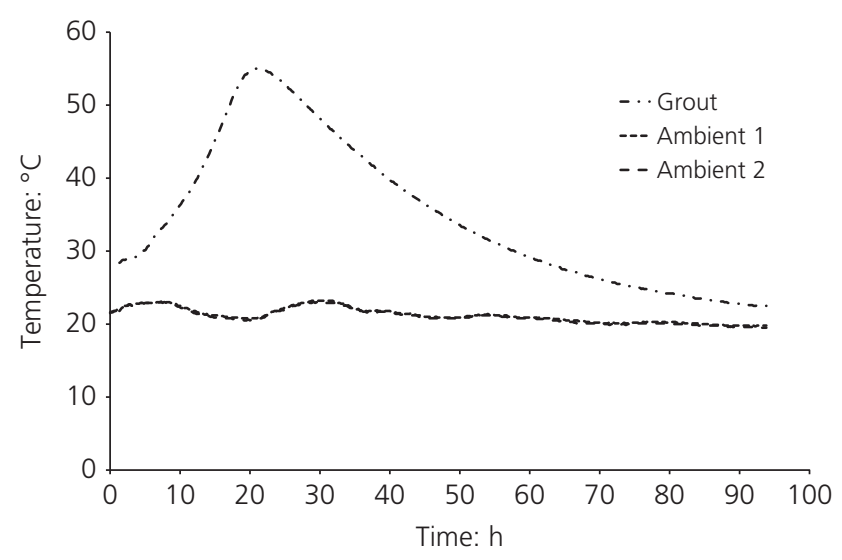

Figure 5. Exotherm of $200 \mathrm{dm}^{3}$ grout product incorporating PCE superplasticiser

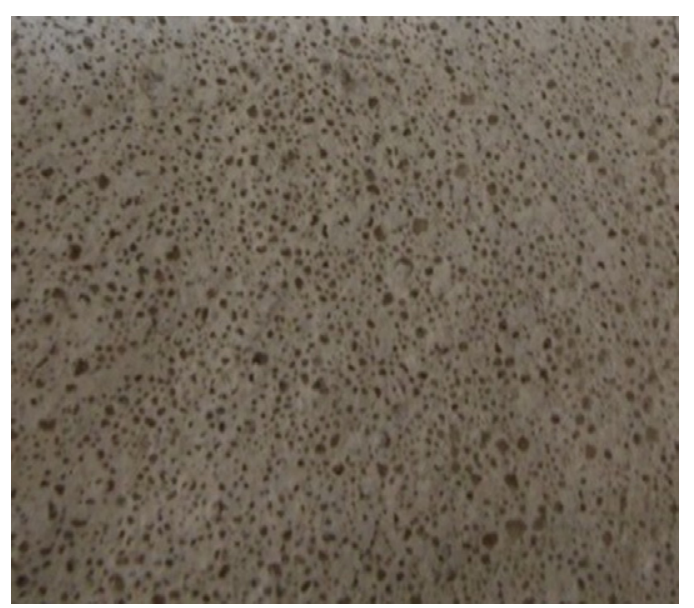

Figure 6. Photograph of set grout product incorporating PCE superplasticiser

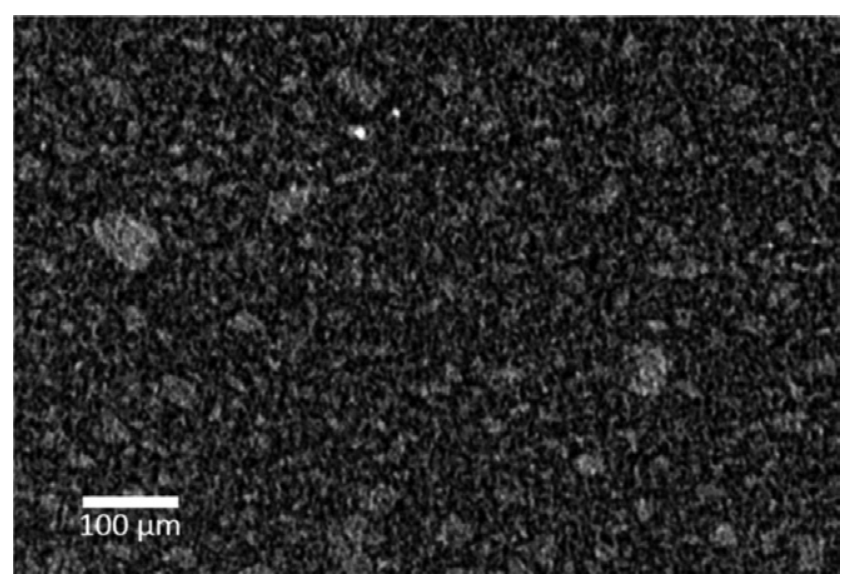

Figure 7. Tomography slice of sample taken from central core of $200 \mathrm{dm}^{3}$ product 
Table 7. Activity of superplasticiser added to the mix and activity measured in the bleed of the samples

\begin{tabular}{|lcccc|}
\hline Replicate & Activity of superplasticiser added: Bq & Bleed mass: $\mathbf{g}$ & Bleed water activity: Bq & Superplasticiser in bleed: \% \\
\hline 1 & 18376 & 1.090 & 85.22 & 0.46 \\
2 & 17109 & 1.262 & 83.88 & 0.49
\end{tabular}

maximum exotherm for grouted ILW products of $100^{\circ} \mathrm{C}$ (to prevent steam generation). These results are consistent with the relatively low cumulative heat of hydration measured for this system after $24 \mathrm{~h}$ discussed previously, although for plant processes it is recommended that higher CEM I ratio blends are also tested.

\section{Air entrainment in $200 \mathrm{dm}^{3}$ product}

A photograph of the set product (Figure 6) shows an aerated surface, which suggests a degree of air entrainment during mixing. This was anticipated as the synthesised pure PCE had no de-foaming agent, whereas commercial formulations typically contain these in order to reduce entrained air (Xiao et al., 2014). This tallies with the measured cube density for strength measurements of $1.92 \mathrm{~kg} / \mathrm{dm}^{3}$ being below the theoretical grout density of $2 \mathrm{~kg} / \mathrm{dm}^{3}$, again indicating air entrained in the final product. Entrained air was not present in the small-scale products, primarily due to the lower speed of mixing, which does not aerate the mix to the same degree.

An X-ray microtomography slice representative of the product as a whole is shown in Figure 7. The entirety of the middle and upper core and the majority of the lower core exhibit typical cement structure and cement pore networks with no obvious foaming structures present. The dark regions in Figure 7 are of low density, indicating air and water, and suggesting that the entrained air was incorporated in the interconnecting porosity rather than as discrete air bubbles as seen at the top surface of the product. Although a small number of bubbles (ranging from $75-130 \mu \mathrm{m}$ diameter) were present in the lowermost core, these were sparsely distributed and atypical of the other samples.

\section{Small-scale product assessment}

In order to determine the distribution of the superplasticiser within the cement grout - whether irreversibly/reversibly adsorbed onto the cement during hydration, lost in the bleed water or retained within the pore water $-\mathrm{a}{ }^{14} \mathrm{C}$-labelled PCE was synthesised and used in the formation of cement blocks weighing $50 \mathrm{~g}$. The bleed collected from the prepared blocks was used to approximate the percentage of superplasticiser remaining within the blocks, either adsorbed onto the solid or within the pore water. Almost all of the polymer was shown to remain within the monolith, with only $\sim 0.5 \%$ of the active material present within the bleed water (Table 7).

The distribution of PCE in a cured grout is shown in Figure 8. There was a mostly homogenous distribution throughout

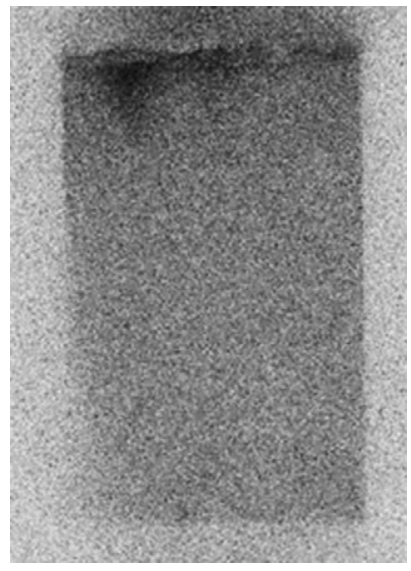

Figure 8. Autoradiograph of block produced with a ${ }^{14}$ C-labelled PCE

the block, although there was a slight increase in the amount present near the top surface. This may be due to the PCE initially present in the bleed that was reabsorbed into the grout, increasing the concentration at the top of the block. If this is the case, it suggests that superplasticisers preferentially adsorb onto solid materials rather than existing in free solution.

The concentration of superplasticiser within the pore water of the blocks was determined by TOC analysis of samples produced from the pore expression of grouts produced with unlabelled PCE that had been cured for $28 \mathrm{~d}$. An unexpectedly high volume of pore water was expressed from all of the samples, although a lower volume was observed from the samples made with a $1 \%$ bwoc dosage of superplasticiser. This is likely due to greater consolidation where a high superplasticiser dosage was used, reducing the available pore space and increasing the volume of bleed water. Despite the high volume of pore water produced, the TOC of the samples was quite low, corresponding to between $6-15 \%$ of the superplasticiser initially added to the cement paste (Table 8). The low TOC in the pore water, in conjunction with the low values of superplasticiser found in the bleed water, suggest that $85-93 \%$ of the inventory of the added superplasticiser remains within the solid phases of a young cement. This finding is in agreement with the results reported by Fujita et al. (2008), where <90\% of the superplasticiser was shown to remain in the solid phase. It is important to determine whether this distribution would remain the same as the cement ages because if the superplasticiser is immobilised on the cement solids, then the possibility of mobilisation of radionuclides is decreased. 
Table 8. Volume collected and TOC data of pore water collected from pore extraction of a grout from blocks produced with $0,0 \cdot 5$ and $1 \%$ superplasticiser loadings

\begin{tabular}{|c|c|c|c|c|c|c|c|}
\hline Sample & $\begin{array}{l}\text { Superplasticiser } \\
\text { dose: bwoc }\end{array}$ & $\begin{array}{l}\text { Monolith } \\
\text { mass: } \mathbf{g}\end{array}$ & $\begin{array}{c}\text { Mass of pore } \\
\text { water collected: } \mathbf{g}\end{array}$ & $\begin{array}{c}\text { Pore } \\
\text { water pH }\end{array}$ & $\begin{array}{l}\text { TOC: } \\
\text { ppm }\end{array}$ & $\begin{array}{l}\text { TOC mass in } \\
\text { pore water: } \mathrm{g}\end{array}$ & $\begin{array}{l}\text { Organic carbon } \\
\text { added: } \%\end{array}$ \\
\hline PCE 1 & 0.5 & $160 \cdot 49$ & $7 \cdot 75$ & $12 \cdot 7$ & 18.9 & 0.0146 & 9.74 \\
\hline PCE 2 & 0.5 & $177 \cdot 39$ & $9 \cdot 37$ & $12 \cdot 7$ & $10 \cdot 8$ & 0.0101 & $6 \cdot 76$ \\
\hline PCE 1 & 1 & $163 \cdot 35$ & $4 \cdot 23$ & $12 \cdot 7$ & $104 \cdot 2$ & 0.0440 & 14.69 \\
\hline PCE 2 & 1 & $167 \cdot 51$ & $4 \cdot 28$ & $12 \cdot 7$ & $61 \cdot 4$ & 0.0262 & 8.76 \\
\hline Blank 1 & 0 & $176 \cdot 42$ & $7 \cdot 56$ & $12 \cdot 8$ & 1.6 & 0.0012 & N/A \\
\hline Blank 2 & 0 & $168 \cdot 12$ & 8.39 & $12 \cdot 7$ & 2.6 & 0.0021 & N/A \\
\hline
\end{tabular}

\section{Conclusions}

The work presented shows that the processing criteria for current ILW encapsulation grouts can be met using BS EN standard GGBS powder by the incorporation of a pure, synthesised PCE superplasticiser at a low w/s ratio, producing a highly fluid, low-viscosity mix, despite some evidence of particle segregation. Heat of hydration curves confirmed that the peak exotherm was well below SL encapsulation plant limits and that incorporation of the PCE did not significantly alter the hydration process for a high GGBS replacement grout with the peak exotherm measured well below current limits. Product evolution studies for the PCE-incorporated grout indicated that, while there was evidence of some air entrainment, high strengths were achieved over a $90 \mathrm{~d}$ curing period with dimensional stability results well within acceptable ranges for ILW encapsulation grouts. Therefore, the PCE-incorporated formulation used in this study also met current product criteria for encapsulation grouts. Studies into the distribution of radiolabelled PCE within a hardened grout showed that very little of the PCE added was present within the bleed or in the pore water and likely remained adsorbed onto solid phases. The results suggest that the introduction of a purified PCE superplasticiser may allow the use of cement industry standard powders for ILW encapsulation processes, allowing lower water content matrices. This, in turn, may mitigate the risk of future powder supply issues.

\section{Acknowledgement}

The authors would like to thank the Nuclear Decommissioning Authority for funding M. Isaacs' $\mathrm{PhD}$ studentship.

\section{REFERENCES}

Angus M, Borwick J, Cann G et al. (2011) The specification of cement powders for waste encapsulation processes at the Sellafield site. Proceedings of Nuwcem 2011, Avignon, France. INIS IAEA, Vienna, Austria, pp. 48-58.

ASTM (2014) C 490: Standard practice for use of apparatus for the determination of length change of hardened cement paste, mortar and concrete. ASTM International, West Conshohocken, PA, USA.

Baum H and Ben-Bassat M (1999) Effect of superplasticisers on some properties of fresh and hardened concrete mixes. Proceedings of International Rilem Conference on the Role of Admixtures in High
Performance Concrete (Cabrera JG and Rivera-Villarreal R (eds)). RILEM, SARL Bagneux, France, pp. 482-492.

BSI (2002) BS EN 13395-2:2002: Products and systems for the protection and repair of concrete structures. Test methods Determination of workability. Test for flow of grout or mortar. BSI, London, UK

BSI (2006) BS EN 15167-1:2006: Ground granulated blast furnace slag for use in concrete, mortar and grout - part 1: definitions, specifications and conformity criteria. BSI, London, UK.

BSI (2008) BS EN 196-3:2005+A1:2008: Methods of testing cement. Determination of setting times and soundness. BSI, London, UK

BSI (2009) BS EN 12390-3:2009 Testing hardened concrete, part 3: compressive strength of test specimens. BSI, London, UK.

BSI (2011) BS EN 197-1:2011 Cement - part 1: composition, specifications and conformity for common cements. BSI, London, UK.

Cann G, Harrison S, Borwick J and Dixon H (2015) Assessment of Port Talbot Blast Furnace Slag. NNL, Warrington, UK, NNL (15) 13542.

Clacher A, Baston G, Glasser F, Jauffret G and Swanton S (2013) Effects of ADVA Cast 551 Superplasticiser on Radionuclide Solubility. NDA, Harwell, UK, AMEC 006180/003 Issue 01.

Fantinel F, Rieger J, Molnar F and Hubler P (2004) Complexation of polyacrylates by $\mathrm{Ca}^{2+}$ ions. Time-resolved studies using attenuated total reflectance Fourier transform infrared dialysis spectroscopy. Langmuir 20(7): 2539-2542.

Fujita H, Haga K, Shibata M and Mihara M (2008) Concentration and molecular weight of superplasticizer contained in pore solution extracted from hardened cement pastes. Journal of Advanced Concrete Technology 6(3): 289-395.

Greenfield B, llett D, Ito M et al. (1998) The effect of cement additives on radionuclide solubilities. Radiochimica Acta 82(S1): 27-32.

Hanehara S and Yamada K (1999) Interaction between cement and chemical admixture from the point of cement hydration, absorption behaviour of admixture, and paste rheology. Cement and Concrete Research 29(8): 1159-1165.

Hesse C, Goetz-Neunhoeffer F and Neubauer J (2011) A new approach in quantitative in-situ XRD of cement pastes: correlation of heat flow curves with early hydration phases. Cement and Concrete Research 41(1): 123-128.

Isaacs M, Hinchliff J, Felipe-Sotelo M and Read D (2017) Factors affecting the suitability of superplasticiser-amended cement for the encapsulation of radioactive waste. Advances in Cement Research (accepted).

Jansen D, Goetz-Neunhoeffer F, Lothenbach B and Neubauer J (2012) The early hydration of Ordinary Portland Cement (OPC): an approach comparing measured heat flow with calculated heat flow from QXRD. Cement and Concrete Research 42(1): 134-138.

Leemann A, Lothenbach B and Thalmann C (2011) Influence of superplasticizers on pore solution composition and on expansion of concrete due to alkali-silica reaction. Construction and Building Materials 25(5): 344-350. 
Lothenbach B, Winnefeld F and Figi R (2007) The influence of superplasticisers on the hydration of Portland cement. Proceedings of the 12th International Congress on the Chemistry of Cement, Montreal, Canada. EMPA, Dübendorf, Switzerland, pp. W1-5.03. Nirex (2005) Generic Repository Studies. Generic Waste Packaging Specification. Volume 1 - Specification. Nirex, Didcot, UK, Nirex report N/104.

Puertas F, Santos H, Palacios M and Martinez-Ramirez S (2005) Polycarboxylate superplasticiser admixtures: effect on hydration, microstructure and rheological behaviour in cement pastes. Advances in Cement Research 17(2): 77-89, http://dx.doi.org/ 10.1680/adcr.2005.17.2.77.

Uchikawa H, Hanchara S and Sawaki D (1997) The role of steric repulsive force in the dispersion of cement particles in fresh paste prepared with organic admixture. Cement and Concrete Research 27(1): $37-50$.
Wieland E, Lothenbach B, Glaus M, Thoenen T and Schwyn B (2014) Influence of superplasticisers on the long term properties of cement pastes and possible impact on radionuclide uptake in a cement-based repository for radioactive waste. Applied Geochemistry 49(1): 126-124.

Winnefeld F, Becker S, Pakusch J and Götz T (2007) Effects of the molecular architecture on the properties of comb-shaped superplasticizers on their performance in cementitious systems. Cement and Concrete Research 29(4): 251-262.

Xiao R, Deng Z and Shen C (2014) Properties of ultra high performance concrete containing superfine cement and without silica fume. Journal of Advanced Concrete Technology 12(2): 73-81.

Young A, Warwick P, Milodowski A and Read D (2013) Behaviour of radionuclides in the presence of superplasticiser. Advances in Cement Research 25(1): 32-43, http://dx.doi.org/10.1680/ adcr.12.00032.

\section{How can you contribute?}

To discuss this paper, please submit up to 500 words to the editor at journals@ice.org.uk. Your contribution will be forwarded to the author(s) for a reply and, if considered appropriate by the editorial board, it will be published as a discussion in a future issue of the journal. 